\title{
15
}

\section{Digital strangers, digital natives: Challenging the norm to create Change@SouthAustralia}

\author{
Erma Ranieri
}

When I was asked to contribute on the subject of managing our workforces' generational divide, I thought that while I'm not really across technology, I am across the workforce. As the Commissioner for Public Sector Employment in South Australia, I oversee a workforce of around 104,000. In my chapter, I wish to explore how we, as a public sector, grapple with a changing platform for our citizens. In other words, how the public sector needs to set policy in the era of co-design, social media, big data, participatory budgeting and social enterprises. This is a significant challenge for any government- to start to think about how the institution of government, many hundreds of years old, has to change.

First, let me outline what South Australia has been doing through the Change@SouthAustralia program, which I have been leading, and what probably led to my being appointed as Commissioner for Public Sector Employment. Change@SouthAustralia arose from the premier, in collaboration with the Economic Development Board, declaring the need for cultural change in the public service. I was in another government agency at the time and was asked to come on board to lead Change@ SouthAustralia. 
The first step was to find people who can be innovative and make changes, irrespective of how old they are. They then, through a series of 90-day projects, were required to demonstrate that the public sector can find new ways of working; their projects were required to bypass the layers of bureaucracy and move into what we call digital by default. What was surprising to me was not that it was the digital innovators who came up with the solutions, it was that the solutions were co-designed.

None of these projects were done without the involvement of either business or citizens that were affected by them; together, we defined a problem and devised a solution. Often in government, by contrast, what we do is present the same thing in different formats: an app or a website that tells people what to do, rather than inviting them to co-design the solution. There is much to be said for instead focusing on systemic reform. We found, through these 90-day projects, the ownership of and solutions to a particular problem shouldn't just be the public sector, but include the views of the citizens we serve. But how do you go about obtaining that public value and engagement? You speak to the customers. That's what we did with the projects and, in doing so, explored the best solutions. We achieved some great outcomes as a result, some of which I will share with you now.

Perhaps the most important step was realising just how entrenched the barriers are around doing things in government. We have lots of really great silos. They're very healthy. So, we interrogated our procedures. We challenged the norm and tried to reduce red tape. And we succeeded. We identified over 700 of what we called 'simplified red tape ideas'. The problem is, the moment you start to unpack and undo that red tape, you get hit with more. Consequently, it's about saying 'I'm going to stop doing it' and so I've decided to stop doing some things as long as it's not in contradiction to the law.

Change@SouthAustralia has now completed 75 projects. With no extra staff. This equates to 75 (and counting) different projects that have been driven by people from outside of government suggesting what needs to change. This doesn't mean we don't still need the input of our employees for the process to be successful; we have over 100,000 at our disposal. Some of them have focused on digital solutions and we have used the principles of digital by default; we have noticed over the last few years that 
more and more of the problems we tackle are finding digital solutions. The outcome of this is that more and more public sector employees have a safe place to explore the opportunities presented by digital.

Sometimes, these solutions can become quite scary because, in fact, they are making jobs redundant-increasingly, the public can do things for themselves online that public servants would have previously done for them. Consequently, not everyone is going to embrace this sort of change. But the fact that Change@SouthAustralia provides an opportunity to fail — and the public sector tends to be afraid of failure-is one of its strengths. So the trial, in fact, was perfect.

I view any kind of program that allows innovation on the edges to be what I call a viral solution. Such an approach disrupts the norms and spreads new attitudes across the sector. Both of which we did. We have started to create a new public sector culture that celebrates innovation, seeks to find the best solutions and provides the best service; a public sector with a culture founded on the values that we spent so much time on. We need to then embed, I think, values around collaboration and about respecting diversity. Because if I'm going to get into the debate about Gen X, Gen Y, digital natives or digital strangers, we're talking about differencesand all of those differences are in the citizens and community that we actually serve.

All the Change@SouthAustralia projects use collaboration. You cannot do it on your own, it has to be with multiple agencies. We consult with industry, we engage with citizens and we integrate multiple reform tools. And it has to contribute to the vision of the state: it's not okay to do things that don't make a difference to anyone.

Consider the following examples of 90-day projects, completed with no extra investment. One is a real-time app that tells passengers when their next bus, tram or train will arrive and how late it will be. Another slashed processing times through the police and courts for minor offences. In another project, the Environment Protection Authority and the Department of Primary Industries and Regions South Australia got together and reduced the licensing period for tuna fishers from five weeks to five days. There are hundreds of other examples that demonstrate where and how we can do similar things. These aren't so much digital solutions as cases of talking to the people and the industries involved about what 
needs to change. In doing so, I like to think, through thinking outside the box and outside the traditional role of government regulation, we are helping business in South Australia to thrive.

Another of our projects centred on nurses discharging healthy patients. This started as another 90-day project and arose from the realisation that a criteria-led discharge was something that would save, in terms of productivity and time, a significant amount of money. Indeed, we were told the only reason it didn't already exist was fear over subsequent industrial action, either from doctors, nurses or paramedics. Everyone involved seemed content with the status quo. So the challenge for us was to think differently about what could be done.

We also had an Unleashed Open Data Competition project that changed South Australia from effectively having a closed government to an open one. This brings me to big data or open data. When we started, only two agencies were prepared to release their data, the rest deeming theirs too confidential to release. We sent the departments that had declined another letter, this one signed by the premier, saying we needed them to participate in the GovHack, Australia's largest open government and open data hackathon. This time we received 217 data sets from 27 organisations. So what is stopping us now that we have the data? What are we collecting it for and how do we put it to use? Ultimately, how can it best be harnessed to help government assist businesses and citizens to make decisions for themselves? These are questions we are attempting to answer.

Finally, let me fast forward to my role as commissioner now. How, in that capacity, do I ensure we work harder at our engagement strategy? It comes down to how do we, as a public sector, shift to where we need to be to enable greater, better collaboration and all that comes with it? Easier said than done.

The first thing I did was to reissue the code of ethics; one change we made was to consider it in terms of values-based decision-making, and start to introduce the challenges of social media and what it is to be in the public eye. By this, I mean what it is for citizens to find out about what public sector does, what it is to actually open it and start to set the parameters for people-whether they be digital strangers or natives. Ultimately, what we need to do is make sure that people are clear about what they can and cannot do, and how we can co-locate and work together in a new kind of setting. 
That will not be easy as we try to move from old settings to new. We need to approach things with a new, principles-based approach, and I would like to emphasise the need to get rid of the rules that actually stop us from doing things. Solutions will come in new patterns of engagement; simple changes to how we engage with community, how it becomes almost the norm for us working in government, how we reflect those new ways through our workforce and are reflective of the entire community that we serve. We need to celebrate the diversity of that community. And, as a public sector, we need to consider how we can use digital to be able to give people the sort of information they're looking for. That way we can both have a positive impact on their lives and ensure we remain relevant for the next 10 to 15 years. 
This text is taken from Opening Government: Transparency and Engagement in the Information Age, edited by John Wanna and Sam Vincent, published 2018 by ANU Press, The Australian National University, Canberra, Australia.

doi.org/10.22459/OG.04.2018.15 